
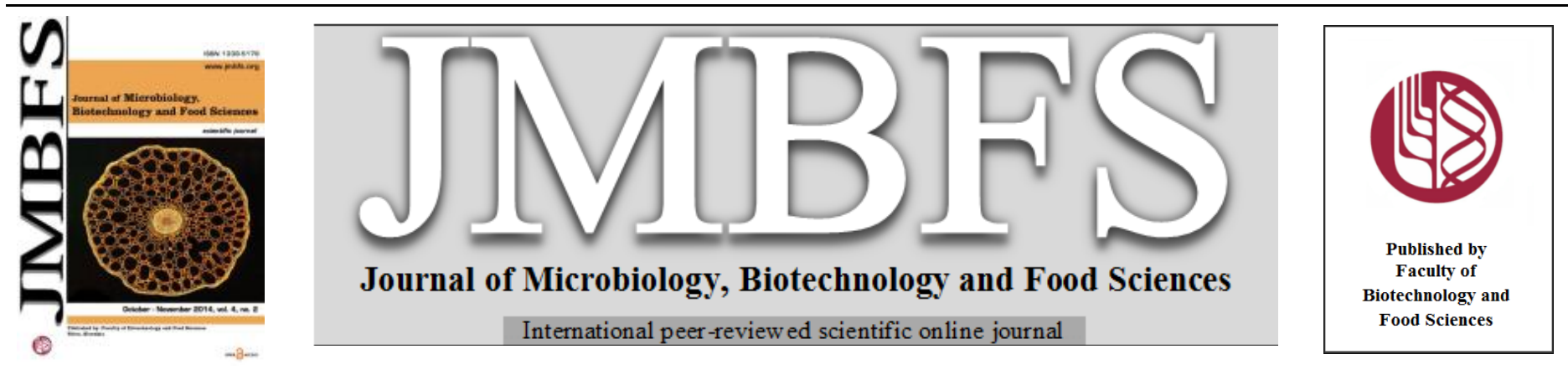

\title{
MORPHO-MOLECULAR SCREENING OF RICE (ORYZA SATIVA L.) GENOTYPES AT SEEDLING STAGE FOR SALT TOLERANCE
}

\author{
Ali Julfiker Md. Masud ${ }^{1}$, Md. Abunasar Mia ${ }^{1}$, Mirza Mofazzal Islam ${ }^{2}$, Shamsun Nahar Begum ${ }^{2}$, Shamsul H. Prodhan ${ }^{\text {* }}$
}

\author{
Address(es): \\ ${ }^{1}$ Department of Genetic Engineering and Biotechnology, Shahjalal University of Science and Technology, Sylhet-3114, Bangladesh. \\ ${ }^{2}$ Bangladesh Institute of Nuclear Agriculture, Mymensingh- 2200, Bangladesh.
}

*Corresponding author: shamsulhp@yahoo.com

doi: 10.15414/jmbfs.2014.4.2.164-169

\section{ARTICLE INFO}

Received 20. 8. 2014

Revised 17.9. 2014

Accepted 18. 9. 2014

Published 1. 10. 2014

Regular article

OPEN $\partial_{\text {ACCESS }}$

\begin{abstract}
Providing adequate food to meet an escalating population is one of the gravest problems the humankind is now facing. To resolve this crisis identification of salt tolerant rice variety is very vital. So, in this research, ten rice genotypes were used to screen salinity tolerance at the seedling stage in hydroponic system using SSR markers. Salinity screening was done at glasshouse following IRRI standard protocol using two setups of salinized and non-salinized conditions. Genotypes under controlled condition had longer root and shoot length then salt stress genotypes. Parental polymorphism survey was done with ten SSR markers viz., RM336, RM510, RM7075, RM407, RM3201b, RM10748, AP3206f, RM3412, RM585, RM11504 and all were selected to evaluate salt tolerance in rice genotypes. The number of alleles per locus ranged from 3 (AP3206f) to 9 (RM336), with an average of 6.1 alleles across 10 loci obtained in the study. The polymorphic information content values ranged from of 0.54 (AP3206f) to a high of 0.86 (RM336) with an average of 0.74 . The pair-wise comparisons of Nei's (1973) genetic distance (D) between varieties were computed from combined data for the 10 primers, ranged from 0.30 to 0.90 with an average of 0.86 , while the similarity index based analysis ranged from 0.00 to 0.70 . Finally, the FL-478, FL-378, Binadhan-8 and Binadhan-10 were selected as salt tolerant because they showed tolerance in phenotypic analysis. These phenotypically selected tolerant genotypes could be used for the selection of suitable parents and development of salt tolerant rice varieties.
\end{abstract}

Keywords: Rice, salinity tolerance, SSR markers, seedling stage, polymorphism

\section{INTRODUCTION}

Rice (Oryza sativa L.), an agricultural crop is a member of the family Gramineae (Poaceae) is one of the agronomically and nutritionally important cereal crops. It is a staple food grain in Asia, providing food to more than half of the world population (Chong and Deng, 2007) and is cultivated on about one-tenth of the earth's land suitable for growing crops (El-Shabrawi et al., 2010). It places nex to wheat (Chakravarthi et al., 2006). To meet up the growing demand for rice, it has been estimated that global annual rice production needs to be increased from the present 560 million tons to 850 million tons by 2025 (Khush and Virk, 2001)

Recently, Salt stress is the second most widespread soil problem in rice growing countries next to drought and considers as major restriction to cereal production worldwide (Gregorio et al., 1997). As a result, development of salt tolerant rice varieties have become a demand for increasing rice production in saline prone coastal regions.

Screening a large number of genotypes for salt tolerance is not easy. Salinity affects plants at all stages of development, but the response of rice to salinity varies with growth stage. Rice is susceptible to salinity during two periods of its growth cycle. The first is the seedling stage and the second begins a few days before panicle initiation and ends with flowering and pollination. Screening of rice germplasms for salt tolerance at seedling stage is accepted readily because it is based on a simple criterion of selection, it facilitates rapid screening of large number of materials and the results are reproducible. Screening under controlled condition has the advantage of reduced environmental effects and the hydroponic system is free from the problems associated with soil related stress factors. Breeding for salt tolerance using conventional screening and selection methods have been limited by the complex and polygenic nature of salt tolerance trait(Gregorio et al., 1997). This hinders the development of an accurate, rapid and reliable screening technique.

However, with the progress in plant biotechnology, as an aiding tool to traditional breeding, molecular markers technique has become a powerful tool to improve salt tolerance of rice by mapping and tagging of genes involved in the control of growth and yield under stressful environments (Haq et al., 2009). Amongst the
DNA markers, the microsatellites also known as simple sequence repeats (SSRs) are useful as genetic markers because they detect high levels of allelic diversity and immensely used in marker assisted selection (MAS). Microsatellite markers based on SSRs have been developed in many crop species including rice, tomato, soybean and others. A very large quantity of microsatellite markers is now easily able to be used through the published high-density linkage map (McCouch $\boldsymbol{e t}$ al. 2002; IRGSP., 2005).

SSR Marker could be applied to trace the flow of genes or QTLs of interest in rice (Islam., 2004) and to make a forecast about the outcome of crossing and selection programs that will help for cultivar development. The present study has been carried out to screen rice genotypes under salinized and nonsalinized conditions and to find out suitable microsatellite markers for the detection of salt tolerant genotypes at the seedling stage.

\section{MATERIAL AND METHODS}

Plant materials

The experiment was conducted at the BINA glasshouse and Biotechnology Laboratory of Biotechnology Division, Bangladesh Institute of Nuclear Agriculture (BINA), Mymensingh, Bangladesh .Ten rice genotypes with widely varied genetic background were used in this study. These genotypes (tab 1) were collected from the Bangladesh Institute of Nuclear Agriculture (BINA). 
Table 1 List of 10 test genotypes for salinity screening.

\begin{tabular}{lll}
\hline S1.No. & Genotypes & Types \\
\hline 1 & Binadhan-7 & Short duration, salt susceptible \\
2 & Binadhan-8 & Salt tolerant \\
3 & Binadhan-10 & Salt tolerant \\
4 & NARICA-1 & Drought tolerant \\
5 & NARICA-4 & Drought tolerant \\
6 & NARICA-10 & Drought tolerant \\
7 & Ciherang-sub1 & Submergence tolerant \\
8 & Samba Mashuri- & Submergence tolerant \\
9 & sub1 & Salt tolerant \\
10 & FL-378 & Salt tolerant \\
\hline
\end{tabular}

\section{Phenotypic Study of Salinity Tolerance at Seedling Stage}

Using IRRI standard protocol (Gregorio et al., 1997), the genotypes were screened for salt tolerance at seedling stage in hydroponic system. Salinized and non-salinized setups with 2 replications were maintained. The experiment was done using Peters Professional ${ }^{\circledR}(20-20-20)$ water soluble fertilizer, where Nitrogen $(\mathrm{N})=20 \%$, available Phosphate $(\mathrm{P} 2 \mathrm{O} 5)=20 \%$ and soluble Potash $(\mathrm{K} 2$ $\mathrm{O})=20 \%$.To Prepare peter's solution 1g Peters Professional ${ }^{\circledR}(20-20-20)$ water soluble fertilizer was dissolved in 1 litre of tap water. Finaly, $110 \mathrm{mg} / \mathrm{L}$ Ferrous Sulphate $(\mathrm{FeSO} 4.7 \mathrm{H} 2 \mathrm{O})$ was added. The nutrient solution was salinized by adding crude salt to obtain desired EC $(12 \mathrm{dS} / \mathrm{m})$. The modified standard evaluation system (SES) (Gregorio et al., 1997) was used in rating the visual symptoms of salt toxicity which discriminated the susceptible from the tolerant and the moderately tolerant genotypes. Initial and final scoring was done at 12 days and 30 days after salinization.

\section{Data Collection}

The data were collected from the screening at seedling stage in both nonsalinized and salinized conditions following IRRI Standard Evaluation System (Gregorio et al., 1997). Leaves, shoots and roots of individual rice plant were collected from glasshouse and kept into separate packet in a convection oven for 5 days at $60^{\circ} \mathrm{C}$ for drying and then weighted using a digital weight machine. $\%$ of reduction of total dry matter, \% reduction of shoot length and root length were calculated as follows:

Total Dry Matter $(\mathrm{TDM})=$ dry weight of leaves + dry matter of roots + dry matter of shoots.

Percent of reduction of total dry matter $(\mathrm{RTDM})=\{(\mathrm{TDM}$ at control conditionTDM at saline condition) / TDM at saline condition $\} 100$.

Percent of reduction of shoot length $(\mathrm{RSL})=\{$ (shoot length at control conditionshoot length at saline condition)/ shoot length at saline condition $\} 100$.

Percent of reduction of root length $(\mathrm{RRL})=\{$ (root length at control conditionroot length at saline condition)/ root length at saline condition $\} 100$.

\section{Genotyping of salinity tolerance}

For isolation of genomic DNA, young, actively growing fresh leaves were collected from 21-day old seedlings. DNA was extracted from rice leaves using the IRRI miniprep protocol. Ten SSR primer pairs were selected on the basis of the published rice microsatellite framework map for the genetic diversity analysis of the 10 rice genotypes ( $\mathrm{Tab} 2$ ).

Table 2 The sequence and size of the microsatellite markers (SSRs) used for primer selection

\begin{tabular}{|c|c|c|c|c|}
\hline $\begin{array}{l}\text { Primer } \\
\text { Name }\end{array}$ & SSR repeat motif & Primer sequence & Annealing temp. $\left({ }^{\circ} \mathrm{C}\right)$ & $\begin{array}{l}\text { Expected PCR } \\
\text { Product size (bp) } \\
\end{array}$ \\
\hline RM336 & (CTT) 18 & $\begin{array}{l}\text { F. primer- cttacagagaaacggcatcg } \\
\text { R. primer- gctggtttgttcaggttcg }\end{array}$ & 55 & 154 \\
\hline RM407 & (AG) 13 & $\begin{array}{l}\text { F. primer- gattgaggagacgagccatc } \\
\text { R. primer- cttttcagatctgegctcc }\end{array}$ & 55 & 172 \\
\hline RM510 & $(\mathrm{GA}) 15$ & $\begin{array}{l}\text { F. primer- aaccggattagtttctcgcc } \\
\text { R. primer- tgaggacgacgagcagattc }\end{array}$ & 55 & 122 \\
\hline RM585 & (TC) 45 & $\begin{array}{l}\text { F. primer- cagtcttgctccgtttgttg } \\
\text { R. primer-ctgtgactgacttggtcatagg }\end{array}$ & 55 & 233 \\
\hline RM7075 & $(\mathrm{ACAT}) 13$ & $\begin{array}{l}\text { F. primer- tatggactggagcaaacctc } \\
\text { R. primer- ggcacagcaccaatgtctc }\end{array}$ & 50 & 155 \\
\hline RM8094 & (AT)31 & $\begin{array}{l}\text { F. primer- aagtttgtacacatcgtataca } \\
\text { R. primer- cgcgaccagtactactacta }\end{array}$ & 55 & 209 \\
\hline RM10748 & (AG)14 & $\begin{array}{l}\text { F. primer- catcggtgaccaccttctcc } \\
\text { R. primer-cctgtcatctatctccctcaagc }\end{array}$ & 55 & 95 \\
\hline RM11504 & $(\mathrm{AAG}) 18$ & $\begin{array}{l}\text { F. primer tcgtctttgagcccaccatattcg } \\
\text { R. primer- cgcaccagcaccettgtatcc }\end{array}$ & 55 & 281 \\
\hline RM3412b & -- & $\begin{array}{l}\text { F. primer- tgatggatctctgaggtgtaaagagc } \\
\text { R. primer- tgcactaatctttctgccacagc }\end{array}$ & -- & -- \\
\hline AP3206f & -- & $\begin{array}{l}\text { F. primer- gcaagaattaatccatgtgaaaga } \\
\text { R. primer- agtgcaggatctgccatga }\end{array}$ & -- & -- \\
\hline
\end{tabular}

*Motif of the SSR and number of repeats as previously published (http://www.gramene.org)

All 10 primers showed clear polymorphism that were used in genotyping the genotypes. Information regarding the original source, repeat motifs, primer sequences, expected length, chromosomal localizations and repeat types of the SSRs can be found in the Web database (http://www.gramene.org). For microsatellite assay PCR amplification carried out with $10.0 \mu \mathrm{l}$ containing $1.0 \mu \mathrm{l}$ of $10 \mathrm{X}$ buffer, $0.2 \mu \mathrm{l}$ of dNTPs, $0.5 \mu \mathrm{l}$ of primer forward and $0.5 \mu \mathrm{l}$ of primer reverse, $0.2 \mu \mathrm{l}$ of taq polymerase, $3.4 \mu \mathrm{l}$ of sterilized ddH2O , $1.2 \mu \mathrm{MgCl}_{2}$ and 3 $\mu 1$ of each template DNA. The PCR initially denatured at $94^{\circ} \mathrm{C}$ for $5 \mathrm{~min}$ followed by 34 cycles of $94^{\circ} \mathrm{C}$ for $1 \mathrm{~min}$., Primer Annealing at $55^{\circ} \mathrm{C}$ for $1 \mathrm{~min}$ and $2 \mathrm{~min}$ for Primer Extension at $72^{\circ} \mathrm{C}$, finally $7 \mathrm{~min}$ incubation at $72^{\circ} \mathrm{C}$. For checking amplification, the PCR products were electrophoreticaly resolved in vertical electrophoresis tank, run on $8 \%$ polyacrylamide gels in $1 \%$ TBE buffer. The gel was soaked in ethidium bromide $(10 \mathrm{mg} / \mathrm{ml})$ solution for 20 minutes. The gels were viewed by the GEL Doc. The size of the amplified fragments was determined by comparing the migration distance of amplified fragments relative to the molecular weight of known size markers, 20 base pairs (bp) DNA ladder using Alpha-Ease FC 5.0 software (Alpha Innotech, USA). The number of alleles per locus, major allele frequency, gene diversity and PIC values were calculated using PowerMarker version 3.25 (Liu \& Muse., 2005). All the genotypes were scored for the presence and absence of the SSR bands throughout all 10 genotypes and the data were exported to binary data for further analysis with NTSYS-pc version 2.2 (Rohlf., 2002) NTSYS-pc was used to construct a UPGMA (unweighted pair group method with arithmetic averages) dendrogram showing the distance-based interrelationship among the genotypes.

\section{RESULTS AND DISCUSSION}

\section{Screening of genotypes for salt tolerance at seedling stage}

All genotypes were grown robustly and showed uniform green colour and height in the non-salinized condition. In salinized condition, the genotypes showed wide variation in phenotypes ranging from score 1 (highly tolerant) and score 9 (highly susceptible) (Fig. 1) (Tab 3).

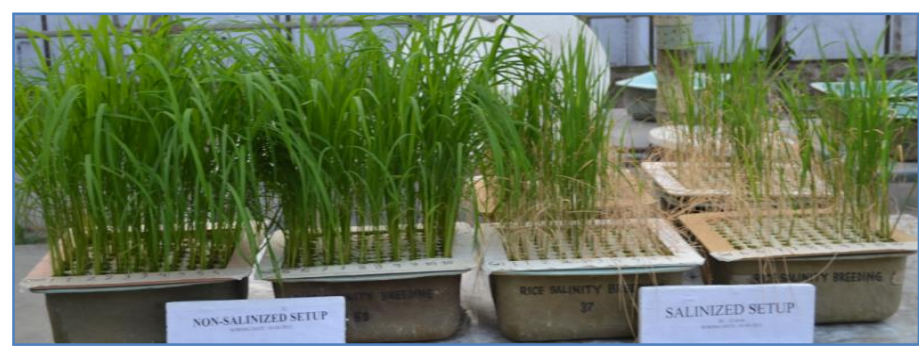

Figure 1 Setups of non-salinized and salanized conditions of 10 rice genotypes (after 30 days) at seedling stage using hydroponic system with EC level $12 \mathrm{dS} / \mathrm{m}$. 
Table 3 Performance of the 10 rice genotypes under salinized condition (EC 12 $\mathrm{dS} / \mathrm{m}$ ) grown in hydroponic system at the seedling stage.

\begin{tabular}{|c|c|c|c|c|c|}
\hline \multirow{2}{*}{$\begin{array}{l}\text { Sl. } \\
\text { NO. }\end{array}$} & \multirow{2}{*}{$\begin{array}{l}\text { Name of the } \\
\text { varieties }\end{array}$} & \multicolumn{3}{|c|}{ SES Score } & \multirow{2}{*}{$\begin{array}{c}\text { Salinity } \\
\text { Tolerance at } \\
\text { seedling stage }\end{array}$} \\
\hline & & $\begin{array}{c}12 \\
\text { DAS }\end{array}$ & $\begin{array}{c}18 \\
\text { DAS }\end{array}$ & $\begin{array}{c}30 \\
\text { DAS }\end{array}$ & \\
\hline 1 & Binadhan-7 & 3 & 5 & 7 & S \\
\hline 2 & Binadhan-8 & 1 & 1 & 3 & $\mathrm{~T}$ \\
\hline 3 & Binadhan-10 & 1 & 3 & 3 & $\mathrm{~T}$ \\
\hline 4 & NARICA-1 & 3 & 7 & 9 & HS \\
\hline 5 & NARICA-4 & 3 & 7 & 9 & HS \\
\hline 6 & NARICA-10 & 3 & 7 & 9 & HS \\
\hline 7 & Ciherang-sub1 & 1 & 3 & 7 & $\mathrm{~S}$ \\
\hline 8 & $\begin{array}{l}\text { Samba } \\
\text { Mashuri-sub1 }\end{array}$ & 1 & 5 & 7 & $\mathrm{~S}$ \\
\hline 9 & FL-378 & 1 & 3 & 3 & $\mathrm{~T}$ \\
\hline 10 & FL-478 & 1 & 1 & 3 & $\mathrm{~T}$ \\
\hline
\end{tabular}

Among the ten tested genotypes, salinity tolerant germplasms were Binadhan- 8 Binadhan-10, FL-378 and FL-478. Three salt susceptible genotypes were identified as Binadhan-7, Cherang sub-1, Samba Mashuri sub-1. NARICA-1, NARICA-4, and NARICA-10 were identified as highly salt susceptible genotypes. Salinity affected the plant height, root length and total dry matter (Tab 4).

Table 4 Performance of plant height, root length and total dry matter of 10 rice genotypes at seedling stage at hydrophonic system

\begin{tabular}{|c|c|c|c|c|c|c|c|c|c|c|}
\hline \multirow{2}{*}{ Sl. No. } & \multirow{2}{*}{ Genotypes } & \multicolumn{3}{|c|}{ Plant height $(\mathrm{cm})$} & \multicolumn{3}{|c|}{ Root lenght $(\mathrm{cm})$} & \multicolumn{3}{|c|}{ Total dry weight (gm) } \\
\hline & & Non-salinized & Salinized & $\%$ Reduction & Non-salinized & Salined & $\begin{array}{c}\% \\
\text { Reduction }\end{array}$ & Non-salinized & Salinized & $\%$ Reduction \\
\hline 1 & Binadhan-7 & 51.67 & 31.14 & 39.73 & 21.5 & 18.9 & 12.09 & 1.55 & 0.656 & 57.68 \\
\hline 2 & Binadhan-8 & 46.1 & 39 & 15.4 & 17.67 & 17 & 3.79 & 1.65 & 1.27 & 23.03 \\
\hline 3 & Binadhan-10 & 60.5 & 43.5 & 28.09 & 20.5 & 20.2 & 1.46 & 1.86 & 1.5 & 19.35 \\
\hline 4 & NERICA-1 & 50.33 & 30.16 & 40.07 & 26.5 & 20.33 & 23.28 & 1.28 & 0.61 & 52.34 \\
\hline 5 & NERICA-4 & 53.17 & 28.5 & 46.39 & 24.33 & 16.17 & 33.54 & 1.39 & 0.518 & 62.73 \\
\hline 6 & NERICA-10 & 50.83 & 24.5 & 51.8 & 23.33 & 14.17 & 39.26 & 1.31 & 0.425 & 67.56 \\
\hline 7 & Ciherang-sub1 & 47.83 & 29.17 & 39.01 & 18.83 & 17.17 & 8.82 & 1.24 & 1.057 & 14.76 \\
\hline 8 & $\begin{array}{l}\text { Samba Mashuri- } \\
\text { sub1 }\end{array}$ & 38.5 & 20.83 & 45.89 & 22 & 14.83 & 32 & 0.55 & 0.306 & 44 \\
\hline 9 & FL-378 & 48.17 & 32.33 & 32.88 & 21.5 & 20.4 & 5.12 & 1.3 & 1.086 & 16.46 \\
\hline 10 & FL-478 & 60 & 44.67 & 25.55 & 18.17 & 17.83 & 1.87 & 2.27 & 1.894 & 16.56 \\
\hline
\end{tabular}

Under salinity stress there were lower reductions in plant height of varieties Binadhan-8 (15.5\%), FL-478 (25.55\%), Binadhan-10 (28.09\%), and FL-378 $(32.88 \%)$. Highest reduction $(51.8 \%)$ in plant height was observed by the variety NARICA-10 (51.8\%) followed by NARICA-4 (46.39\%), NARICA-10 (51.8\%), NARICA -1 (40.07\%), Binadhan-7 (39.73\%), Ciherang sub-1and Samba Mashuri sub-1. The percent reduction of total dry matter ranged from 16-67. Under salinity stress some genotypes showed higher reduction of total dry matter (Ali \& Awan ., 2004). These include NARICA-10 (67.57\%), NARICA-4 (62.73\%), NARICA-1 (52.34\%), and Binadhan-7 (57.68\%) Samba Mashuri sub-1 (44\%) Some genotypes showing lower reduction were FL-378 (16.46\%), FL-478 (16.56\%), Binadhan-10 (19.35\%), Binadhan-8 (23.03\%), and Ciherang sub-1 $(14.76 \%)$

\section{Screening with SSR markers}

Ten markers were used to evaluate genotypes for salinity tolerance. Amplified microsatellite loci were analyzed for polymorphism using polyacrylamide gel electrophoresis and the result revealed that all the primer pairs detected polymorphism among the rice genotypes analyzed. Microsatellite profiles of 10 rice genotypes at loci RM7075, RM10748, RM3412b, AP3201b, RM407 were shown in Figure 2. The result revealed that all the primer pairs were detected polymorphism among the rice genotypes analyzed.
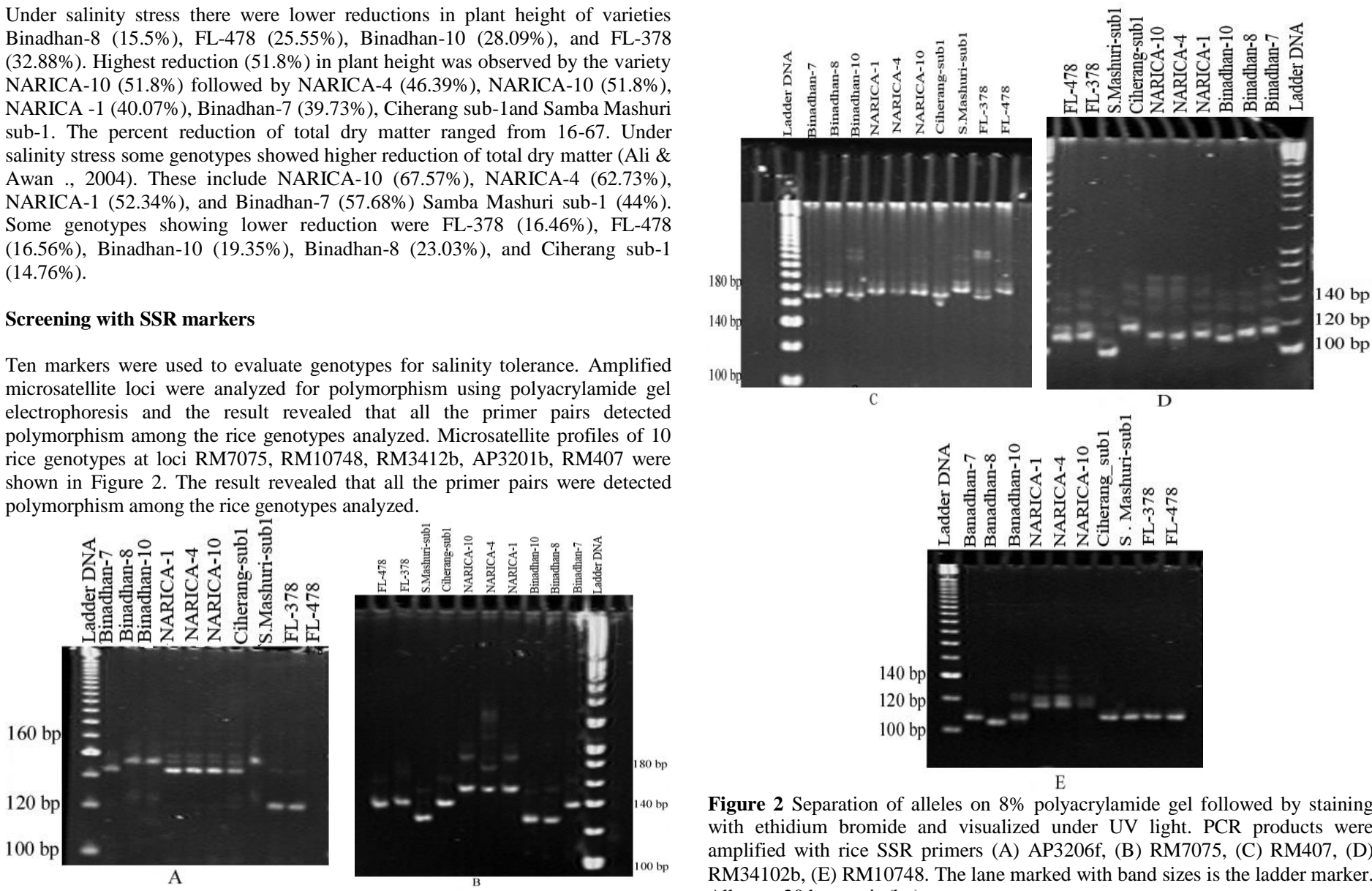

Figure 2 Separation of alleles on $8 \%$ polyacrylamide gel followed by staining with ethidium bromide and visualized under UV light. PCR products were amplified with rice SSR primers (A) AP3206f, (B) RM7075, (C) RM407, (D) RM34102b, (E) RM10748. The lane marked with band sizes is the ladder marker. All were 20 base pair (bp). 


\section{Size and frequency of alleles}

In respect of primer RM3412b allele size ranged (102bp-114bp), whereas primer RM7075 gave a range from 128bp to $154 \mathrm{bp}$, primer RM407 gave a range from $169 \mathrm{bp}$ to $178 \mathrm{bp}$, primer RM10748 gave a range from $127 \mathrm{bp}$ to $137 \mathrm{bp}$, primer
AP3206f gave a range from $141 \mathrm{bp}$ to $151 \mathrm{bp}$, RM510 primer give a range from 148 -157bp, RM8094 primer give a range from 162-176 bp, RM366 primer give a range from 151-201 bp (Tab 5).

Table 5 Data on repeat motif, number of alleles, number of rare alleles, PIC value and gene diversity (GD) found among 10 rice genotypes for 8 microsatellites (SSR)

\begin{tabular}{|c|c|c|c|c|c|c|c|}
\hline Locus & Repeat Motif* & $\begin{array}{l}\text { Allele Size range } \\
\text { (bp) }\end{array}$ & Differences (bp) & Allele No & $\begin{array}{c}\text { Rare } \\
\text { Alleles* }\end{array}$ & Gene Diversity & PIC \\
\hline RM336 & (CTT)18 & $151-201$ & 50 & 9 & - & 0.88 & 0.86 \\
\hline RM407 & $(\mathrm{AG}) 13$ & $169-178$ & 9 & 7 & - & 0.84 & 0.81 \\
\hline RM510 & (GA)15 & $148-157$ & 9 & 7 & - & 0.84 & 0.81 \\
\hline RM585 & (TC)45 & $167-229$ & 62 & 6 & - & 0.70 & 0.67 \\
\hline RM7075 & (ACAT)13 & $128-154$ & 26 & 7 & - & 0.82 & 0.79 \\
\hline RM8094 & (AT)31 & $162-176$ & 14 & 6 & - & 0.80 & 0.77 \\
\hline RM10748 & $(\mathrm{AG}) 14$ & $127-137$ & 10 & 5 & - & 0.72 & 0.67 \\
\hline RM11504 & (AAG) 18 & $246-266$ & 20 & 5 & - & 0.76 & 0.72 \\
\hline RM3412b & -- & $102-114$ & 12 & 6 & - & 0.80 & 0.77 \\
\hline AP3206f & -- & $141-151$ & 10 & 3 & - & 0.62 & 0.54 \\
\hline Mean & & & & 6.1 & - & 0.77 & 0.74 \\
\hline
\end{tabular}

\section{Number of alleles per locus}

Using 10 SSR markers, a total of 61 alleles were detected among the 10 rice genotypes. The average number of allele per locus was 6.1 , with a range of 3 (AP3206f) to as many as 9 (RM336) (Tab 5). Nearly similar observation (Jain et al., 2004) was found where the number of allele per locus ranged from 3 to as high as 22 with average number of allele per locus 7.8 .

\section{Rare Alleles}

An allele observed in less than $5 \%$ of the 24 accession was considered to be rare allele (Jayamani et al., 2007). In general marker detecting a greater number of alleles per locus detected more rare alleles.

\section{Allele size range}

The size variation between the smallest and the largest allele at a given SSR locus was correlated with the number of alleles per locus. Thus, RM510 presented the smallest allele size range (9bp) and had 7 alleles in RM510, while RM336 had the largest number of alleles (9) with a allele size range (50 bp) (Tab 5). The other primers such as RM7075 showed allele size range $26 \mathrm{bp}$, whereas RM10748 had the allele size range 10bp.

\section{Gene diversity}

According to Nei's (Nei., 1973) the highest level of gene diversity value (0.88) was observed in loci RM336 and RM8094, the lowest level of gene diversity value (0.62) was observed in loci AP3206f with a mean diversity of 0.77 (Tab
5). It was observed that marker detecting the lower number of alleles showed lower gene diversity than those detected higher number of alleles which revealed higher gene diversity. The maximum number of repeats within the SSRs was also positively correlated with the genetic diversity.

\section{PIC values}

As a measure of the informativeness of microsatellites, the PIC values ranged from a low of 0.54 (AP3206f) to a high of 0.86 (RM336) and averaged 0.74 (Tab 5). PIC values also showed a significant, positive correlation with the number of alleles and allele size range for microsatellites evaluated in this study. The allele size range and the number of alleles were themselves also highly correlated.

\section{Major allele}

Major allele is defined as the allele with the highest frequency and also known as most common allele at each locus. The frequency of the most common allele at each locus ranged from 20\% (RM336, RM407 and RM510) to 50\% (RM585 and AP3206f) with a mean frequency of $32 \%$. The average number of sample size was 10 with an average number of observations 10 . The size of the differen major alleles at different loci ranges from 110bp (RM3412b) to 174bp (RM585).

\section{Genetic distance-based analysis}

Pair-wise comparisons of Nei's (1973) genetic distance (D) between varietie were computed from combined data for the 10 primers, ranged from 0.30 to 0.90 (Tab 6).

Table 6 Summary of (Nei's, 1973) genetic distance values for 10 rice genotypes

\begin{tabular}{|c|c|c|c|c|c|c|c|c|c|c|}
\hline OTU & Binadhan-7 & $\begin{array}{l}\text { FL- } \\
478\end{array}$ & $\begin{array}{c}\text { Binadhan- } \\
8\end{array}$ & $\begin{array}{c}\text { Binadhan } \\
-10\end{array}$ & $\begin{array}{c}\text { NARICA } \\
-1\end{array}$ & $\begin{array}{c}\text { NARICA } \\
-4\end{array}$ & $\begin{array}{c}\text { NARICA- } \\
10\end{array}$ & $\begin{array}{l}\text { Ciherang- } \\
\text { sub1 }\end{array}$ & $\begin{array}{c}\text { Samba Mashuri- } \\
\text { sub1 }\end{array}$ & $\begin{array}{l}\text { FL- } \\
378\end{array}$ \\
\hline Binadhan-7 & 0.00 & 1.00 & 1.00 & 0.90 & 0.90 & 0.90 & 0.90 & 0.60 & 0.90 & 1.00 \\
\hline FL-478 & 1.00 & 0.00 & 0.90 & 1.00 & 0.80 & 0.90 & 0.90 & 1.00 & 0.90 & 0.70 \\
\hline Binadhan-8 & 1.00 & 0.90 & 0.00 & 0.70 & 1.00 & 1.00 & 0.90 & 0.90 & 0.80 & 0.80 \\
\hline Binadhan-10 & 0.90 & 1.00 & 0.70 & 0.00 & 1.00 & 1.00 & 1.00 & 0.70 & 0.80 & 1.00 \\
\hline NARICA-1 & 0.90 & 0.80 & 1.00 & 1.00 & 0.00 & 0.30 & 0.50 & 0.90 & 1.00 & 0.90 \\
\hline NARICA-4 & 0.90 & 0.90 & 1.00 & 1.00 & 0.30 & 0.00 & 0.40 & 0.90 & 1.00 & 0.90 \\
\hline NARICA-10 & 0.90 & 0.90 & 0.90 & 1.00 & 0.50 & 0.40 & 0.00 & 0.90 & 0.90 & 0.80 \\
\hline Ciherang-sub1 & 0.60 & 1.00 & 0.90 & 0.70 & 0.90 & 0.90 & 0.90 & 0.00 & 0.90 & 1.00 \\
\hline $\begin{array}{l}\text { Samba Mashuri- } \\
\text { sub1 }\end{array}$ & 0.90 & 0.90 & 0.80 & 0.80 & 1.00 & 1.00 & 0.90 & 0.90 & 0.00 & 0.80 \\
\hline FL-378 & 1.00 & 0.70 & 0.80 & 1.00 & 0.90 & 0.90 & 0.80 & 1.00 & 0.80 & 0.00 \\
\hline
\end{tabular}

Comparatively higher genetic distance $(0.90)$ was observed between a numbers of genotypes. Some of these are Binadhan-7 vs. NARICA-1, Binadhan-7 vs NARICA-4, FL478 vs. NARICA-1, FL478 vs. NARICA -4, FL478 vs. Ciherang-sub1, Binadhan-8 vs. NARICA-1, Binadhan-8 vs. NARICA-4, Binadhan-8 vs. FL-378, NARICA-1 vs. Cherang-sub1 , NARICA-4 vs. Ciherangsub1 , NARICA-6 vs. Samba Mashuri-sub1 , Binadhan-10 vs. FL-478 . The lowest genetic distance $(0.300)$ was found in Narica-1vs Narica-4 variety pair. The average genetic distance among the 10 rice genotypes was quantified as 0.86 .

\section{Similarity Index Based Analysis}

In this study, the diversity was ranged from 0.00 to 0.70 (Tab 7). 
Table 7 Similarity Index of 10 rice genotypes

\begin{tabular}{|c|c|c|c|c|c|c|c|c|c|c|}
\hline & Binadhan-7 & FL-478 & Binadhan-8 & $\begin{array}{c}\text { Binadhan- } \\
10\end{array}$ & NARICA-1 & NARICA-4 & NARICA-10 & $\begin{array}{l}\text { Ciherang- } \\
\text { sub1 }\end{array}$ & $\begin{array}{c}\text { Samba } \\
\text { Mashuri-sub1 }\end{array}$ & $\begin{array}{l}\text { FL- } \\
378\end{array}$ \\
\hline Binadhan-7 & 1.00 & & & & & & & & & \\
\hline FL-478 & 0.00 & 1.00 & & & & & & & & \\
\hline Binadhan- 8 & 0.00 & 0.10 & 1.00 & & & & & & & \\
\hline Binadhan-10 & 0.10 & 0.00 & 0.30 & 1.00 & & & & & & \\
\hline NARICA-1 & 0.10 & 0.20 & 0.00 & 0.00 & 1.00 & & & & & \\
\hline NARICA-4 & 0.10 & 0.10 & 0.00 & 0.00 & 0.70 & 1.00 & & & & \\
\hline NARICA-10 & 0.10 & 0.10 & 0.10 & 0.00 & 0.50 & 0.60 & 1.00 & & & \\
\hline Ciherang-sub1 & 0.40 & 0.00 & 0.10 & 0.30 & 0.10 & 0.10 & 0.10 & 1.00 & & \\
\hline $\begin{array}{l}\text { Samba Mashuri- } \\
\text { sub1 }\end{array}$ & 0.10 & 0.10 & 0.20 & 0.20 & 0.00 & 0.00 & 0.10 & 0.10 & 1.00 & \\
\hline FL-378 & 0.00 & 0.30 & 0.20 & 0.00 & 0.10 & 0.10 & 0.20 & 0.00 & 0.20 & 1.00 \\
\hline
\end{tabular}

The higest Similarity index value of 0.70 was observed in NARICA-1 vs NARICA-4. A lower similarity value of 0.10 was observed in Binadhan-7 vs NARICA-1, Binadhan-7 vs. NARICA-4, FL-478 vs. Binadhan-8 , FL-478 vs Binadhan-10, FL-478 vs. NARICA-1, FL-478 vs. NARICA-4 , FL-478 vs. Ciherang-sub1, Binadhan-8 vs. NARICA-1, Binadhan-8 vs. NARICA-4, FL-378 vs. Binadhan-10, NARICA-1 vs. Ciherang-sub1 , NARICA -4 vs. Ciherang-sub1 , NARICA-6 vs. Samba Mashuri-sub1.

Comparatively no similarity value was observed a number of accessions.

Genetic similarity analysis using UPGMA (Unweighted Pair Group Method of Arithmetic Means)

A dendrogram was constructed based on the Nei's genetic distance calculated from the 61 SSR alleles generated from the 10 rice genotypes. All 10 rice genotypes could be easily distinguished. The UPGMA cluster tree analysis led to the grouping of the 10 genotypes into 2 major clusters (Figure 3 ).

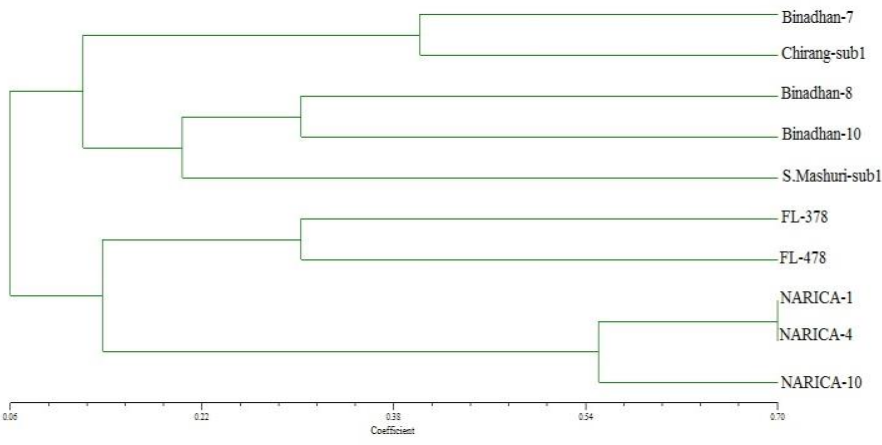

Figure 3 Dendrogram for 10 rice genotypes derived from a UPGMA cluste analysis

\section{DISCUSSION}

In rice, substantial progress has been made in understanding the biology and genetics of tolerance as well as in incorporating tolerance into modern cultivars. Rice plants are most vulnerable to salt stress at seedling stage. Thus, the objectives of this study are to screen salt tolerant rice genotypes at seedling stage and to identify salt tolerant genotypes using SSR markers.

Ten rice genotypes were used for screening salinity tolerance showed wide variation in phenotypes. The symptoms were prominent on the first and second leaves and were visualized by leaf rolling, formation of new leaf, brownish and whitish of leaf tip, drying of leaves and also reduction in root growth, stunted growth, and stem thickness leading to complete cessation of growth and dying of seedlings occurred (Gregorio et al., 1997). These symptoms were also observed by several researchers (Bhuiyan., 2005). The results indicated that plant height was reduced due to salinity stress (Purnenduet al., 2004; Maiti et al., 2006). It is reported that salinity might directly or indirectly inhibit cell division and enlargement during plant growing period. As a result, leaves and stems of the affected plants appeared stunted (Munns and Tester., 2008).

The current research addresses the exploitation of 10 microsatellite markers to reveal genetic polymorphism and ensures definite identification of 10 rice genotypes. The average allele (6.1 alleles) obtained in this investigation was comparable with the result reported by Etemad et al. (2012) detecting 3.57 alleles per SSR locus, who used 26 rice (Oryza sativa, L.) accessions, consisting of 13 Iranian and 13 Malaysian cultivars were investigated using SSR markers dispersed across the rice genome. In another study, Hossain et al. (2012) found an average of 3.8 alleles per locus in rice using Bangladeshi aeromatic rice landraces. Our outcome were also analogous to 2.0-5.5 alleles per SSR locus for different classes of microsatellites reported by Cho et al. (2000), who used a different set of rice germplasm. Wong et al. (2009) reported the genetic relationship and diversity analysis among 8 Bario rice cultivars using 12 SSR primers, detecting a total of 31 alleles. The average number of alleles per locus was 2.6, which is distinctly lower than our report.

The PIC values ranged from a low of 0.5478 (AP3206f) to a high of 0.86 (RM336) and averaged 0.74. PIC values also showed a significant, positive correlation with the number of alleles and allele size range for microsatellites evaluated in this study. The allele size range and the number of alleles were themselves also highly correlated. The gene diversity value was ranged from a 0.62 (AP3206f) to a high of 0.88 (RM336) and averaged 0.77 . The frequency of the most common allele at each locus ranged from 20\% (RM336, RM407 and RM510) to $50 \%$ (RM585 and AP3206f) with a mean frequency of $32 \%$.

The genetic dissimilarities among the 10 rice genotypes were determined using Nei's genetic distance-based analysis. The highest genetic distance (0.90) was observed between Binadhan-7 vs. NARICA-1, Binadhan-7 vs. NARICA-4, FL478 vs. NARICA-1, FL478 vs. NARICA -4, FL478 vs. Ciherang-sub1, Binadhan- 8 vs. NARICA-1, Binadhan-8 vs. NARICA-4, Binadhan-8 vs. FL-378, NARICA-1 vs. Cherang-sub1, NARICA-4 vs. Ciherang-sub1, NARICA-6 vs. Samba Mashuri-sub1, Binadhan-10 vs. FL-478. The higher genetic distance between them indicates that genetically they are diverse compare to lower genetic distance value. Basically, this value is an indication of their genetic dissimilarity. Variety pair with higher value is more dissimilar than a pair with a lower value. The lowest genetic distance (0.30) was found in Narica-1vs Narica-4 variety pair indicating that they are genetically much closer among the varieties. This outcome is comparable to the result reported by Nagaraju (2002) where a sub set of 3 rice groups (including traditional and evolved Basmati and semi dwarf nonBasmati) was analyzed by using 19 SSR loci and 12 inter-SSR-PCR primers where the lowest genetic distance was among the traditional Basmati varieties, while the EB varieties showed the highest genetic distance by both the marker assays and also the average genetic distance for the indica and japonica were 0.67 and 0.48 respectively.

A similarity index determines how closely the current plant community resembles either the potential natural community or some other references community. The similarity index provides a distinct measurement in landraces screening and diversity analysis after Nei's genetic distance based analysis When the value is zero, it indicates that, there is no similarity between the variety pair. In this experiment, Highest similarity value was observed between those varieties pairs which showed lowest genetic distance value in Nei's genetic distance based analysis. The lowest similarity value was observed in most of the varieties just as the highest genetic distance was observer in most of the varieties. Finally, The UPGMA cluster analysis of genetic similarity using Dice coefficient showed that all 10 rice genotypes could be easily distinguished based on the information generated by the 10 SSR markers. As expected, cultivars were separated in two clear groups. The 10 SSR markers also allowed the distinction among accessions studied. The results support the contention that SSR marker systems can distinguish genetically close breeding lines and cultivars, and validate their use in the characterization of rice genotypes accessions.

\section{CONCLUSION}

In this study, 10 rice genotypes were grown in hydrophonic system, in both salinized and non salinized conditions. From this, 4 tolerant rice genotypes viz. FL-378, FL-478, Binadhan-8, and Binadhan-10 were finally identified phenotypically. This study also indicates that SSR technique is simple, rapid and efficient in detecting genetic variability. Eventually, this study will be useful for developing salinity tolerant varieties. Genetic diversity found at the DNA level could be used for designing effective breeding programs aiming to broaden the genetic bases of commercially grown varieties.

Acknowledgments: The authors gratefully acknowledged to the authority of Plant Breeding Division, Bangladesh Institute of Nuclear Agriculture (BINA), Mymensingh, Bangladesh for providing the facilities to carry out this research work. We gratefully acknowledge the cooperation of the Department of Genetic 
Engineering and Biotechnology, Shahjalal University of Science and Technology, Sylhet, Bangladesh.

\section{REFERENCES}

ALI, Y., AWAN, V. 2004. Influence of salinity at seedling stage and on yield and yield components of different rice lines. Intl. J. Biol. Biotechnol, 1(2), 175179 .

BHUIYAN, M R. 2005. Efficiency in evaluating salt tolerance in rice using phenotypic and marker assisted selection. M.Sc. dissertation, Department of Genetics and Plant Breeding, Bangladesh Agricultural University, Mymensingh, Bangladesh.

CHAKRAVARTHI, B K., NARAVANENI, R. 2006. SSR marker based DNA fingerprinting and diversity study in rice (Oryza sativa L). African $J$ Biotechnol,5 (9), 684-688.

CHO ,YG., ISHII, T., TEMNYKH, S., CHEN, X., LIPOVICH, L., MCCOUCH, SR., PARK, WD., AYERS, N., CARTINHOUR. S. 2000. Diversity of microsatellites derived from genomic libraries and GenBank sequences in rice (Oryza sativa L.). Theor. Appl. Genet, 100(5), 713-722.

http://dx.doi.org/10.1007/s001220051343

EL-SHABRAWI, H., KUMAR ,B., KAUL, T., REDDY, M K., SINGLAPAREEK, S L., SOPORY, S K. 2010.Redox homeostasis, antioxidant defense, and methylglyoxal detoxification as markers for salt tolerance in Pokkali rice. Epub, 245(1-4), 85-96.

http://dx.doi.org/10.1007/s00709-010-0144-6

ETEMAD, A., MAZIAH, M., DAUD, SK. 2012. Determination of genetic relatedness among selected rice (Oryza sativa, $L$.) cultivars using microsatellite markers. African Journal of Biotechnology, 11(28), 7158-7165.

GREGORIO, G B., SENADHIRA, D ., MENDOZA, R D. 1997 . Screening rice for salinity tolerance. IRRI Discussion Paper Series no.22. Manila (Philippines), International Rice Research Institute 1-30.

HAQ, T U., AKHTAR ,J T U., NAWAZI S., AHMAD, R. 2009 MorphoPhysiological response of rice (Oryza sativa L.) varities to salinity stress. Pak. $J$. Bot, 41(6), 2943-2956

HOSSAIN, MM., ISLAM, MM., HOSSAIN, H., ALI, MS., TEIXEIRA DA SILVA, JA., KOMAMINE, A., PRODHAN, SH. 2012. Genetic diversity analysis of aromatic landraces of rice (Oryza sativa L.) by microsatellite markers. Genes, Genomes and Genomics, 6(SI1), 42-47.

ISLAM, M M. 2004. Mapping salinity tolerance genes in rice (Oryza satiya L.) at reproductive stage. $\mathrm{Ph}$. D. dissertation. University of the Philippines Los Banos, College, Laguna, Philippines.

JAIN, S., JAIN, R K ., MCCOUCH, S R. 2004. Genetic analysis of Indian aromatic and quality rice (Oryza sativa L.) germplasm using panels of fluorescently-labeled microsatellite markers. Theor Appl Genet, 109 (5), 965977.

http://dx.doi.org/10.1007/s00122-004-1700-2

JAYAMANI, P., NEGRÃO, S., MARTINS, M., MAÇÃS, B ., OLIVEIRA, M

M. 2007 . Genetic relatedness of Portuguese rice accessions from diverse origins as assessed by microsatellite markers. Crop Sci, 47(2), 879-886.

http://dx.doi.org/10.2135/cropsci2006.04.0236

KHUSH, G S.,VIRK, P S. 2001. Rice breeding: Achievement and future strategies. Crop Improvement, 27, 115-144.

LIU, K ., MUSE, SV. 2005. PowerMarker: an intregrated analysis environment for genetic marker analysis. Bioinformatics, 21(9), 2128-2129.

http://dx.doi.org/10.1093/bioinformatics/bti282

MA, H., CHONG, K., DENG, X W. 2007. Rice research: past, present and future. J. Integr. Plant Biol, 49, 729-730.

http://dx.doi.org/10.1111/j.1744-7909.2007.00515.x

MAITI, R K., P. VIDYASAGAR, P., BANERJEE ,P P. 2006. Salinity tolerance in rice (Oryza sativa L.) hybrids and their parents at emergence and seedling stage. Crop Res. Hisar, 31(3) 427-433.

MCCOUCH, SR., TEYTELMAN, L., YUNBI, X U., LOBOS, KB., KAREN, C., WALTON, M., BINYING, F., MAGHIRANG, R., LI, Z., XING, Y., QIFA, Z., IZUMI, K., YANO, M., FJELLSTROM, R., DECLERCK, G., SCHNEIDER, D., CARTINHOUR, S., WARE, D ., STEIN, L. 2002. Development of 2240 new SSR markers for rice (Oryza sativa L.), DNA Research, 9(6), 199-207.

http://dx.doi.org/10.1093/dnares/9.6.199

MUNNS, R ., TESTER, M. 2008. Mechanisms of salinity tolerance. Annu. Rev. Plant Biol, 59(1), 651- 681.

http://dx.doi.org/10.1146/annurev.arplant.59.032607.092911

NAGARAJU ,J., KATHIRVEL, M., KUMAR, R R., SIDDIQ „E A ., HASNAIN, S E. 2002. Genetic analysis of traditional and evolved Basmati and non Basmati rice varieties by using fluorescence based ISSR PCR and SSR markers. Proc Nat Acad Sci, USA, 99(9),5836-5841.

http://dx.doi.org/10.1073/pnas.042099099

NEI, M. 1973. Genetic distance between populations. American Nature, 106(949), 283-292.

http://dx.doi.org/10.1086/282771
PURNENDU, G., MANNAN, M A., PAL, P S., HOSSAIN, M M ., PARVIN ,S 2004. Effect of salinity on some yield attributes of rice. Pak. J. Biol. Sci, 7(5) ,760-762.

ROHLF, F J. 2002. NTSYS-pc: Numerical taxonomy and multivariate analysis system (Ed. 2.2), Department of Ecology and Evolution, State University of NY Stony Brook.

The International Brachypodium Initiative. IRGSP: International Rice Genome Sequencing Project. 2005. The map based sequence of the rice genome. Nature 436 (7282), 793-800.

WONG, SC., YIU, PH., BONG, STW., LEE,HH, NEOH, PNP., RAJAN, A. 2009. Analysis of Sarawak Bario rice diversity using microsatellite markers. Am. J. Agri. Biol. Sci, 4(4), 298-304.

http://dx.doi.org/10.3844/ajabssp.2009.298.304 